'Department of Trauma and Orthopaedics, East and North Hertfordshire NHS Trust, Stevenage, UK

${ }^{2}$ Department of Trauma and Orthopaedics, St Mary's Hospital, London, UK ${ }^{3}$ St Mary's Hospital, London, UK

\section{Correspondence to}

Dr Sarkhell Saadi Radha, sarkhell.orthopaedics@yahoo. co.uk

Accepted 13 March 2014

\title{
Acetabular fracture following penetration of buttock by railing spike: an unusual mechanism of injury needing careful immediate care
}

\author{
Sarkhell Saadi Radha, ${ }^{1}$ Angela $\mathrm{Yu}{ }^{2}$ Junaid Sayani, ${ }^{3}$ Angus Lewis ${ }^{3}$
}

\section{DESCRIPTION}

A 38-year-old woman presented to our trauma centre following a left buttock injury after falling off a three-storey building. The patient landed on a $20 \mathrm{~cm}$ railing spike which pierced her left buttock. The paramedics managed the patient according to the advanced trauma life support protocol while she was still hanging by her buttock on the railing spike. ${ }^{1}$ The rescue team addressed her airway and c-spine, breathing and circulation while minimising moving her to avoid damage to any neurovascular structures. The fire brigade arrived and cut the spike at its base and left it in situ.

On arrival to A\&E she was haemodynamically stable with a $10 \mathrm{~cm}$ deep laceration to her left buttock. Clinically her sciatic nerve had reduced motor power with dorsiflexion of her left foot reduced to a MRC grading of three. CT scan revealed the spike sitting along the posterior column and wall of the acetabulum with a comminuted fracture of the posterior column extending to the ischeal tuberosity with multiple intra-articular fragments (figures 1 and 2). She underwent emergency surgery to remove the metal work, assess the damage and debride the wound. During the operation her sciatic nerve was noted to be extensively bruised and swollen but was in continuity with no evidence of major vascular injuries. A staged reconstruction of the acetabulum

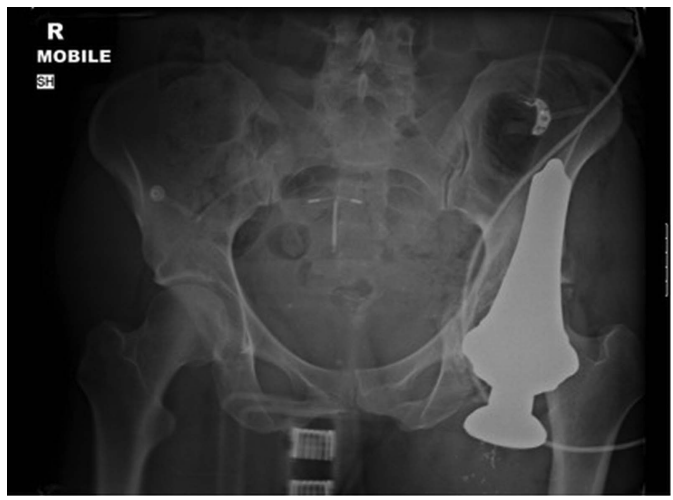

Figure 1 Anteroposterior pelvic X-ray showing metal spike in situ.

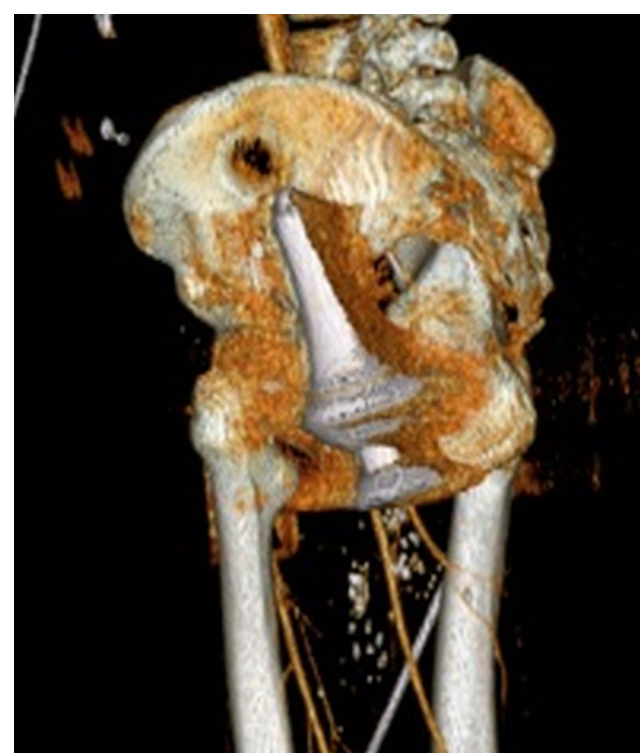

Figure 2 Three-dimensional reconstruction of pelvis with spike injury.

was undertaken 7 days later using a Smith and Nephew recon-plate (figure 3). The patient was rehabilitated by mobilising partial weight bearing on her left leg. Prior to discharge the patient had full sensory and motor function.

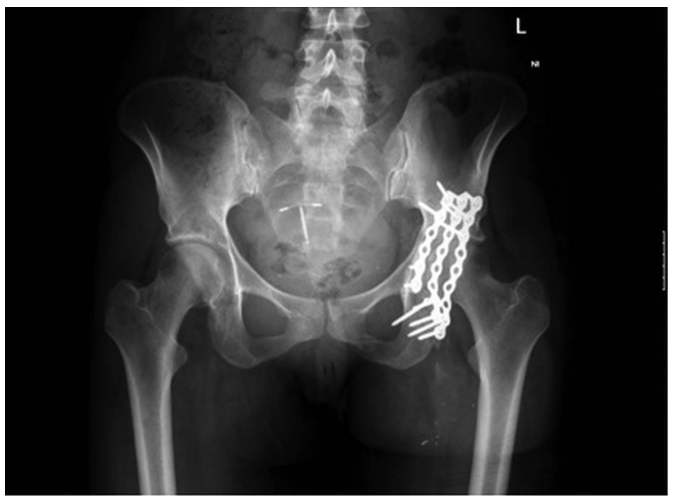

Figure 3 Post fixation anteroposterior pelvic X-ray showing recon plate in situ. 


\section{Learning points}

- This case demonstrates the importance of managing patients systematically using advanced trauma life support principles. ${ }^{1}$ With this unusual mechanism of injury, further injury was prevented by performing a primary survey while the patient was still hanging on the rail instead of attempting immediate removal of the spike, which may have damaged the sciatic nerve permanently.

- This case highlights the importance of preoperative planning and the appropriate management of such an unusual mechanism of injury and highlights the concept of damage control orthopaedics. ${ }^{2}$
Competing interests None.

Patient consent Obtained.

Provenance and peer review Not commissioned; externally peer reviewed.

\section{REFERENCES}

1 American College of Surgeons Committee on Trauma. Advanced trauma life support program for doctors. 8th edn. Chicago: American College of Surgeons, 2008.

2 Roberts CS, Pape HC, Jones AL, et al. Damage control orthopaedics evolving concepts in the treatment of patients who have sustained orthopaedic trauma. J Bone Joint Surg 2005;87:434-49.

Copyright 2014 BMJ Publishing Group. All rights reserved. For permission to reuse any of this content visit http://group.bmj.com/group/rights-licensing/permissions.

BMJ Case Report Fellows may re-use this article for personal use and teaching without any further permission.

Become a Fellow of BMJ Case Reports today and you can:

- Submit as many cases as you like

- Enjoy fast sympathetic peer review and rapid publication of accepted articles

- Access all the published articles

- Re-use any of the published material for personal use and teaching without further permission

For information on Institutional Fellowships contact consortiasales@bmjgroup.com

Visit casereports.bmj.com for more articles like this and to become a Fellow 